Physiology (Bethesda). 2010 December ; 25(6): 338-346. doi:10.1152/physiol.00026.2010.

\title{
Olfactory Learning in Drosophila
}

\author{
Germain U. Busto, Isaac Cervantes-Sandoval, and Ronald L. Davis \\ Department of Neuroscience, The Scripps Research Institute Florida, Jupiter, Florida \\ rdavis@scripps.edu
}

\begin{abstract}
Studies of olfactory learning in Drosophila have provided key insights into the brain mechanisms underlying learning and memory. One type of olfactory learning, olfactory classical conditioning, consists of learning the contingency between an odor with an aversive or appetitive stimulus. This conditioning requires the activity of molecules that can integrate the two types of sensory information, the odorant as the conditioned stimulus and the aversive or appetitive stimulus as the unconditioned stimulus, in brain regions where the neural pathways for the two stimuli intersect. Compelling data indicate that a particular form of adenylyl cyclase functions as a molecular integrator of the sensory information in the mushroom body neurons. The neuronal pathway carrying the olfactory information from the antennal lobes to the mushroom body is well described. Accumulating data now show that some dopaminergic neurons provide information about aversive stimuli and octopaminergic neurons about appetitive stimuli to the mushroom body neurons. Inhibitory inputs from the GABAergic system appear to gate olfactory information to the mushroom bodies and thus control the ability to learn about odors. Emerging data obtained by functional imaging procedures indicate that distinct memory traces form in different brain regions and correlate with different phases of memory. The results from these and other experiments also indicate that cross talk between mushroom bodies and several other brain regions is critical for memory formation.
\end{abstract}

The most commonly studied form of learning and memory in the fruit fly, Drosophila melanogaster, is olfactory classical conditioning. This may appear surprising given the remarkable visual system of insects with their compound eyes that monitor a large fraction of three-dimensional space, but there are several reasons why olfactory classical conditioning has dominated the Drosophila learning literature so far. One reason is that flies are particularly good at learning about odors, at least in the laboratory. This has provided the opportunity for obtaining quantifiable and reliable measures of learning and memory, which itself is no small feat since animal behavior can be inherently unstable and unreliable. A second reason is that the olfactory nervous system of insects is remarkably homologous in structure and function to that of vertebrates (13), providing assurance that the principles learned will be conserved across animal phyla. A third reason is that olfactory classical conditioning-a type of learning in which an organism learns about the association between an odor and a reinforcer such as mild electric shock or a food reward-is learned rapidly. This provides for a discrete and short training phase followed by memory decay, memory consolidation into stable forms of memory, and retrieval. The discrete phases of acquisition (learning), memory stability/consolidation, and retrieval allow behavioral measures and disruptive treatments to be presented at different times across these phases. This is in contrast to other forms of learning that may require multiple training trials across hours or days to promote memory that is sufficiently stable to be measured and manipulated.

(C2010 Int. Union Physiol. Sci./Am. Physiol. Soc.

No conflicts of interest, financial or otherwise, are declared by the author(s). 
Olfactory classical conditioning (Pavlovian conditioning) requires flies to associate an odor used as a conditioned stimulus (CS) with a negative (electric shock) or positive (sucrose reward) stimulus used as an unconditioned stimulus (US). Classically, this process is performed using groups of flies alternatively submitted to two different odors, a CS+ and a CS-, with only one of them (CS+) presented at the same time as the US $(2,52,60)$. Memory of this conditioning is then tested in a T-maze where the trained flies must choose between the two odors. This procedure is performed with groups of flies, usually about 50, trained and tested together. By increasing the time between acquisition and testing, it is possible to measure short, middle, or longer-lasting forms of memory.

The association between the odorant and the US changes the behavioral value associated with the odor. The plasticity associated with this value change must take place in a region of the central nervous system where olfactory and US information intersect. Pharmacological and genetic inactivation techniques have been employed to identify brain regions involved in making the association. Most of the studies have shown that the integrity or synaptic output of the mushroom bodies (MB) is required for normal olfactory learning $(16,17,42$, 50). Parallel molecular genetic studies have revealed that various molecules involved in cAMP signaling are necessary in MB neurons for normal learning (14). Thus MB neurons are believed to be the primary neurons within the olfactory nervous system at which the associations take place.

\section{Processing of Olfactory Information En Route to the MB Neurons}

Information about the CS constituted by the odor is presented to the MBs by neurons upstream in the olfactory nervous system (FIGURE 1A). The odorants in the environment first bind to the olfactory receptor $(\mathrm{OR})$ proteins expressed on the dendritic surface of $\mathrm{OR}$ neurons (ORNs) (26). The binding of the odorants on the ORs initiates a signal transduction cascade within the ORNs leading to the subsequent depolarization of the stimulated neurons. The ORNs respond to odors by generating specific sequences of action potentials that appear to represent odor quality, quantity, and duration (22). Approximately 1,300 ORNs are localized in the antennae and maxillary palps of the Drosophila head $(13,27)$. Each ORN expresses only one receptor of the $\sim 62$ olfactory receptor proteins that have been identified (9) together with a putative co-receptor or chaper-one protein, Or83b (26).

ORNs project their axons to the antennal lobe (AL). Within this structure, ORNs form synapses in glomeruli with projection neurons $(\mathrm{PN})$ and local excitatory or inhibitory interneurons involved in the local processing of the olfactory information (FIGURE 1B). The glomeruli are synapse-dense, spherical neuropil structures that contribute to the interpretation of signals from the ORNs. All of the axons of ORNs expressing the same OR project to the same glomerulus, even though the cell bodies of the ORNs expressing the same OR are distributed around the periphery of the antennae and maxillary palps $(10,19)$. Each odorant thus activates a specific set of glomeruli, creating a glomerular pattern of activation in the AL that is conserved between flies $(48,62)$. In initial studies, Wang et al. observed that odor delivery elicited similar activation patterns in the ORN axons and in PN dendrites expressing calcium reporters for those two neuronal populations (62). Sensory input was therefore thought to be transmitted rather faithfully from the first-order to the second-order neurons, where each odor is represented by a distinct and sparse spatial pattern of activity of the sensory or projection neurons. More recent electrophysiological studies have suggested that the PNs may be more broadly tuned to odors than their corresponding ORNs (4). The difference in results obtained may be due to the uncertain relationship between calcium signal and neuronal spiking (41). 
Approximately 180 PNs extend their axons to a region of the MBs called the calyx and to another region of the brain called the lateral horn (LH; FIGURE 1B). MB neurons $(\sim 2,500$ per hemisphere) also project their dendrites to the calyx and synapse with the axons of PNs. The representation of olfactory information was studied using whole cell recordings or calcium imaging in the MB neurons following odor stimulation $(61,63)$. The data obtained using both approaches indicate that the response of MB neurons for odors is highly selective and that the odor representation is sparse. Furthermore, calciumimaging indicates that the spatial location and distribution of MB neurons showing calcium transients is similar between flies. Thus a given odorant may be spatially represented by the activity of a small set ( $2 \%)$ of MB neurons (63).

Three types of MB neurons have been described: $\alpha / \beta, \alpha^{\prime} / \beta^{\prime}$, and $\gamma(11,32)$. Each MB cell projects one axon that extends into the neuropil regions of the MBs that are termed "lobes." The $\alpha / \beta$ and $\alpha$ ' $\beta$ ' axons divide in two branches, with the $\alpha$ and $\alpha$ ' branches constituting the vertical lobes of the MBs while the $\beta$ and $\beta$ ' branches constitute the horizontal lobes for these neurons. The $\gamma$ neurons project only to a horizontal lobe.

\section{Dopaminergic Neurons, the US Pathway for Aversive Reinforcements, and the MBs}

Dopamine (DA) is a catecholamine neurotransmitter involved in numerous brain functions including behavior, cognition, learning, and memory. In flies, DA neurons are thought to present information about aversive USs to the MBs (14). There exist five lines of evidence that support this postulate.

The first is that DA neurons extend axons to the MB neuropil and are in proximity to synapse with MB neurons. The cell bodies of DA neurons are grouped in 13 clusters at different locations in the Drosophila brain $(6,39,47)$. The most recent study revealed that only three of these groups (called PAM, PPL1, and PPL2ab) project to the MB neuropil (39). The PPL1 cluster, made up of 12 neurons, consists of four subtypes that differ in their final projection pattern to the vertical lobes of the MBs. The four regions of the vertical lobe targeted by these neurons are 1) the tip of the a lobe, 2) the tip of the a' lobe, 3) the upper stalk, and 4) the lower stalk and its junction with the horizontal lobe. The PPL2ab cluster extends its axons to the MB calyx, and the PAM neurons innervate the horizontal lobes. These studies reveal that DA neurons may synapse onto the dendrites or axons of the MB neurons and reveal that the projections of DA neurons define subcellular compartments of the MB axons that may be important for the processing of sensory and learned information.

The second line of evidence comes from data indicating that electric shock applied to the ventral surface of the fly body evokes a significant calcium signal in DA projections to the MB lobes (53). This finding was confirmed using a second calcium reporter and extended by showing that electric shock pulses induce a robust calcium response in the a lobe and in the lower stalk junction of the MBs (39). These reports indicate that DA neurons are responsive to electric shock and could therefore mediate the US to the MBs.

The third line of evidence involves the effects of blocking synaptic activity of the DA neurons during conditioning. A temperature-sensitive and dominant-negative form of dynamin, which is encoded by the Shibire ${ }^{t s}$ gene and can rapidly block synaptic transmission at restrictive temperatures, was expressed in DA neurons using the Gal4 system (see FIGURE 3). Blocking synaptic transmission of DA neurons just before (15 min) and during acquisition of aversive olfactory conditioning blocked performance $1 \mathrm{~h}$ after conditioning (56). Imposing the synaptic blockade $45 \mathrm{~min}$ after training and only during the retrieval phase was without effect. These results indicate that synaptic release from DA 
neurons at the time of conditioning is required for memory to form, consistent with a role for these neurons in presenting US information.

A fourth line of evidence comes from behavioral studies of DA receptor mutants. Two different D1-like DA receptors are highly expressed in the MB neurons. These receptors are encoded by the dDA1 gene and the DAMB gene $(24,29)$. Although no behavioral effects have yet been reported for DAMB mutants, the dDA1 receptor mutants (named dumb) exhibit little or no learning after olfactory classical conditioning (28). The mutant phenotype of $d u m b$ mutants is rescued with the expression of a wild-type form of the dDA1 receptor specifically in the MB neurons.

Several new channels gated by light have been developed to control neural activity for optogenetic experiments $(37,45)$. Expression of these light-activated channels within the DA neurons has been employed to test whether DA neuron activation is sufficient to provide US information necessary for learning. Schroll et al. (55) and subsequently Claridge-Chang et al. (8) used the light activation of channels expressed in DA neurons to mimic US reinforcement in larvae and adult flies. Both reports suggest that presenting odor coupled with light activation of DA neurons provides sufficient information for aversive odor learning. In the latter study, two different enhancer-trap lines (FIGURE 3) restricting GAL4 expression in different sets of DA neurons were used. Only the line expressing the channel in the PPL1 and PPL2ab clusters provided sufficient light-activatable reinforcement. These results, along with the neuroanatomical results reported by Mao et al. (39) suggest that the PPL1 and/or PPL2ab clusters provide the DA input necessary for aversive olfactory learning.

However, the DA neurons are not likely to be used solely and exclusively as the US pathway for aversive olfactory conditioning. The activity of these neurons has recently been reported to be necessary for appetitive memory as well (30). Robust appetitive memory performance requires the activity of six of the PPL1 DA neurons that innervate the MBs. Blocking synaptic release from these neurons releases memory performance in satiated flies, whereas stimulation suppresses memory performance in hungry flies. In addition, the DA receptor mutant $d u m b$ moderately impairs appetitively reinforced learning (28).

\section{Octopamine Neurons and the US Pathway for Appetitive Reinforcements}

Octopamine (OA) is a biogenic amine that acts as a neurohormone, neuromodulator, and neurotransmitter in arthropods. The identification of an OA receptor gene that is preferentially expressed in the MBs and coupled to adenylyl cyclase suggested an important role for OA in synaptic modulation underlying behavioral plasticity (23). Flies that are mutant for tyramine $\beta$ hydroxylase (T $\beta \mathrm{H})$, an enzyme required for OA synthesis, are impaired after reward learning but not after aversive conditioning. This defect is rescued by feeding mutant flies with OA before training (56). Furthermore, blockade of synaptic release from OA neurons during training of larvae impairs olfactory appetitive conditioning (25). Moreover, the light activation of OA neurons expressing channelrhodopsin paired with odor is sufficient to induce appetitive learning in larvae (55). These observations suggest that OA is necessary and sufficient for reward reinforcement, probably through the activation of OA receptors expressed in MB neurons.

In Drosophila, there are several OA neurons that may be involved in driving the reward US signal to the MBs or the ALs, a second brain area that may be involved in reward-based associations (58). The G5a OA neurons, two neurons located laterally to the ALs, send their axons into the antennal nerve and innervate the AL (57). In addition, at least two VUM1 neurons, located at the ventral surface of the brain, innervate the ALs. These observations may be important because the expression in the ALs of the wild-type gene for rutabaga (rut), 
one of the classic olfactory learning mutants, rescues the olfactory learning deficit of rut mutants (58), which suggests that the integration of odors and appetitive reinforcers may also occur in the ALs. Moreover, at least one neuron of the VUM1 cluster (OA-VUMa2) sends a large axon that ascends via the antennal lobe to the MB calyx (7). These data are consistent with the hypothesis that OA and OA neurons are involved in the US pathway for rewarding stimuli. Nevertheless, these neurons are unlikely to be used exclusively and solely for this purpose, since this neuron also innervates the lateral horn, which may not be involved in memory formation (6).

\section{GABAergic Neurons, Modulation of Learning, and the MBs}

Gamma-amino butyric acid (GABA) is the primary inhibitor neurotransmitter involved in the regulation of neuronal excitability (46). In both mammals and flies, the neuronal circuits that are involved in learning and memory are highly innervated by inhibitory input from GABA. For instance, the hippocampus, which is involved in the formation of multiple types of memories, is densely innervated by GABAergic interneurons (20). The MBs in insects are also innervated by GABAergic interneurons $(36,51,65)$. A recent study showed that a UasGfp reporter, expressed under the control of Gad (glutamic acid decarboxylase)-Gal4 (restricting its expression to GABA neurons), is highly expressed throughout the MB calyces. These projections are thought to form functional synapses in the calyx since GFP is co-expressed with the presynaptic marker synaptobrevin (33).

We recently reported that the MB lobes express the GABA receptor: resistance to dieldrin $(R d I)$ (36). These observations suggested that GABAergic projections have an important role in olfactory memory formation. The restricted overexpression of RDL to the MBs impaired the acquisition of olfactory memory. This effect is not likely due to effects on brain development since the overexpression of RDL was restricted to adulthood using the TARGET system (FIGURE 3). In contrast, knocking down the RDL receptor with RNAi expression in the MBs enhanced acquisition but not memory stability (36). Thus the level of RDL receptor expression in the MBs influences the level of acquisition.

The anterior paired lateral neurons (APL) provide GABAergic input into the MB lobes. The APL cell bodies are located lateral to the MB calyx and near the LH (33). A single-cell clone analysis revealed that the APL neuron sends one projection dorsomedially toward the MBs and bifurcated into two branches. One branch enters the MBs at the waist of the vertical lobes and the other branch enters at the calyx. Blocking the biosynthesis of GABA, by expressing specifically RNAi molecules against GAD in the APL neurons, enhances the acquisition of olfactory memory. Functional imaging of the APL neurons demonstrated that these neurons respond to odor and electrical shock stimulation with increased intracellular calcium levels and neurotransmitter release. In addition, the APL neurons exhibit traininginduced plasticity. The APL neurons show a blunted response to the learned odor 5 min after training. These observations suggest that APL neurons normally suppress olfactory learning by releasing the inhibitory neurotransmitter GABA, which activates the RDL receptors postsynaptically in the MBs. Olfactory learning generates plasticity in the response properties of these neurons; their activity to the learned odor is depressed by conditioning. Since the plasticity in response properties was observed only to the CS (odor) and not to the US, these results also spurred the hypothesis that the GABA system might specifically regulate the CS pathway for olfactory learning. To prove this, we explored the effect of modulating RDL expression level on appetitive olfactory learning using the same CS odors utilized for aversive conditioning (35). The results showed that $R d l$ knockdown in the MBs also impairs the acquisition of appetitive olfactory learning. Thus the GABA/RDL dynamic appears to modulate the strength of the CS signal presented to the MBs after learning. 


\section{Behavioral Memory Phases are Associated with Cellular Memory Traces}

Several different memory phases have been described after Drosophila olfactory classical conditioning (for review see Ref. 3). These include short-term memory (STM), middle-term memory (MTM), anesthesia-resistant memory (ARM), and long-term memory (LTM). One main objective of neuroscience is to elucidate the cellular and molecular changes, or memory traces, that occur in the brain after learning and are associated with changes in behavior. These memory traces can be registered as changes in neuronal excitability, gene or protein expression, or growth or loss of neuronal processes between neurons that establish new or remove old connections.

Several memory traces have been described after a single cycle of training in flies, which is usually performed with a 1-min odor presentation associated with 12 electric shock pulses. Such training induces STM observed within tens of minutes after training and is followed by MTM, which persists for several hours thereafter. This modification in behavior is associated with changes in the synaptic activity of specific PNs in response to CS+ odor presentation in the AL (68). In other words, the memory trace forms because new sets of PNs become activated by the CS+ odor compared with the sets of PNs activated before conditioning. The memory trace is short-lived; it appears within 3 min after training and lasts for only $7 \mathrm{~min}$. These observations suggest that the integration of CS and US may also occur in the AL and therefore at multiple sites in the brain.

Single trial training also enhances the response properties of dorsal paired medial (DPM) neurons to the learned odor $30 \mathrm{~min}$ after training, and thisenhancement persists for at least $60 \mathrm{~min}$ (67). Thus this memory trace forms only after a delay; it is not present at $15 \mathrm{~min}$ after training. Of special interest is the fact that the memory trace is observed as increased calcium influx only into the neuritic branch of the DPM neuron that innervates the vertical lobes of the MBs and not the branch that innervates the horizontal lobes. A similar memory trace appears within the same time window in the $\alpha^{\prime} / \beta^{\prime}$ MB neurons (64). The relationship between these traces is not yet clear, although interconnected loops have been postulated between the MBs and the DPM neurons (67), and this could represent a specialized case between DPM and $\alpha^{\prime} / \beta$ ' MB neurons for memory consolidation (31).

Stronger and longer-lasting memory is generated when training is repeated (usually 5-10 times) with a rest period between each training trial. In Drosophila, spaced training creates olfactory memory that lasts for days and is blocked by inhibitors of protein synthesis administered at the time of training. A specific LTM trace was described and associated with this long-lasting behavior as an increased response to odor stimulation only in the vertical axon branch of the $\alpha / \beta$ MB neurons (66). Like the DPM neuron memory trace, this memory trace is delayed, appearing between 3 and $9 \mathrm{~h}$ after training. It requires the activity of the transcription factor CREB. These discoveries establish that changes induced by protein synthesis after learning can include strengthened responses of synapses and circuit function in specific axonal branches.

But these observations spur additional questions: How is it that a protein synthesisdependent cellular process confers changes localized to a single axon branch and why does this occur only after spaced training? To address the first question, Ashraf et al. (1) designed a fluorescent reporter of synaptic protein synthesis using sequences of the calcium/ calmodulin-dependent protein kinase II (CaMKII) mRNA, which is synthesized at synapses and is required for memory. They showed that olfactory LTM induced mRNA transport and protein synthesis at specific synapses in the AL glomeruli. These results show that training that generates LTM initiates protein synthesis-dependent and lasting changes at specific synapses, thus modifying the naive circuit. 
But what happens during the rest period between training trials? Recent studies with a Drosophila model of Noonan syndrome (NS) identified a disease-associated mutation that impairs memory formation by altering the spacing effect. Pagani et al. (49) demonstrated that the activity of the protein tyrosine phosphatase, CORKSCREW (CSW/SHP2), is tied to the intertrial interval required for LTM induction. Overexpression of wild-type CSW in MB neurons shortened the rest interval between trials required for effective LTM generation, and overexpression of a constitutively activated CSW protein prolonged these intervals. Biochemical measures revealed that spaced training induces repetitive waves of CSWdependent MAPK activation, the length of which appears to define the duration of the rest intervals. CSW activity thus regulates cycles of MAPK activation, identifying this pathway as responsible for the effect of spaced training.

\section{Rut AC as the Molecular Coincidence Detector of the CS and US Pathways in MB Neurons}

Most, if not all, of the molecules involved in Drosophila olfactory learning and memory are expressed in the MB neurons, many of them in a preferential way. This general observation has been detailed elsewhere $(12,15)$. One of these molecules is the enzyme adenylyl cyclase (AC) encoded by rut gene. Mutant flies for rut are deficient in olfactory learning and restricted expression in the adult MB neurons of the wild-type form of rut restores learning $(40,44,69)$.

This form of AC has long been postulated to be critical for the integration of CS and US signals (18). The enzyme is sensitive to both calcium/calmodulin $(\mathrm{Ca} / \mathrm{CaM})$ and $\mathrm{G}$-protein stimulation $(34,38)$. Olfactory learning could thus induce two processes by concurrent application of odor and shock. Stimulation of the US pathway could lead to G-protein activation that is coupled with DA or OA receptors. Stimulation of the CS pathway may cause increased $\mathrm{Ca}^{2+}$ influx in the MB neurons through voltage-sensitive calcium channels.

Through functional imaging experiments of cultured Drosophila brains, Tomchik et al. showed that cAMP is elevated in the MBs with bath application of DA, OA, or acetylcholine (ACh) (59). Focal application of ACh to the MB calyces, mimicking odor signals, or focal application of DA to the MB lobes, mimicking electric shock signals, also increases cAMP accumulation. Most importantly, the application of ACh to the calyces and DA to the lobes together produces a synergistic increase in the cAMP signal (FIGURE 2A). In other words, the level of cAMP generated by the joint application of these neurotransmitters mimicking the simultaneous CS and US signals far exceeds the sum in the level of cAMP generated by each independently. This synergistic effect on cAMP signaling is dependent on the rut AC; rut brains fail to show this synergy. Elevating cAMP levels using forskolin facilitates the calcium responses evoked by ACh, indicating that increases in cAMP levels in the MBs are sufficient to generate plasticity. A subsequent report has confirmed the rut $\mathrm{AC}$ as a coincidence detector for CS and US by imaging the activity of protein kinase A, an effector target of cAMP (21).

Interestingly, the pairing of $\mathrm{OA}$ to the a lobe with $\mathrm{ACh}$ to the calyx produces significantly less cAMP than the sum of each stimulus individually (59) (FIGURE 2B). Thus coincidence of these two neurotransmitters produces a subadditive effect on cAMP accumulation. The meaning of this observation relative to signaling events for aversive vs. appetitive conditioning is not yet clear. But these data at face value suggest that an appetitive stimulus paired with a CS suppresses cAMP responses in the MB neurons. However, this observation is discrepant with results of Gervasi et al., who reported a synergistic effect of paired OA and ACh stimulation on PKA activation (21). The reasons underlying the opposite results are not yet established, but the two groups used different neurotransmitter concentrations, 
molecular reporters, and experimental setups. However, as noted above, DA participates in both appetitive and aversive learning $(28,30)$. Perhaps the US for appetitive conditioning includes the combined action of DA and $\mathrm{OA}$ on MB neurons.

\section{Concluding Remarks}

The molecular tools and genetic tractability of Drosophila have afforded detailed studies and new insights into the mechanisms underlying learning and memory. They have helped to elucidate the neural pathways for the CS and the US, the molecular mediators of CS/US integration, and the real time molecular dynamics of learning. The relatively simple Drosophila brain has permitted the identification of subsets of neurons that participate in different phases of memory formation. +

\section{Acknowledgments}

Research in the Davis laboratory has been supported by grants from the National Institute of Neurological Disorders and Stroke (NS-019904 and NS-052351) and the Ellison Medical Foundation.

\section{References}

1. Ashraf SI, McLoon AL, Sclarsic SM, Kunes S. Synaptic protein synthesis associated with memory is regulated by the RISC pathway in Drosophila. Cell. 2006; 124:191-205. [PubMed: 16413491]

2. Beck CD, Schroeder B, Davis RL. Learning performance of normal and mutant Drosophila after repeated conditioning trials with discrete stimuli. J Neurosci. 2000; 20:2944-2953. [PubMed: 10751447]

3. Berry J, Krause WC, Davis RL. Olfactory memory traces in Drosophila. Prog Brain Res. 2008; 169:293-304. [PubMed: 18394482]

4. Bhandawat V, Olsen SR, Gouwens NW, Schlief ML, Wilson RI. Sensory processing in the Drosophila antennal lobe increases reliability and separability of ensemble odor representations. Nat Neurosci. 2007; 10:1474-1482. [PubMed: 17922008]

5. Brand AH, Perrimon N. Targeted gene expression as a means of altering cell fates and generating dominant phenotypes. Development. 1993; 118:401-415. [PubMed: 8223268]

6. Budnik V, White K. Catecholamine-containing neurons in Drosophila melanogaster: distribution and development. J Comp Neurol. 1988; 268:400-413. [PubMed: 3129458]

7. Busch S, Selcho M, Ito K, Tanimoto H. A map of octopaminergic neurons in the Drosophila brain. J Comp Neurol. 2009; 513:643-667. [PubMed: 19235225]

8. Claridge-Chang A, Roorda RD, Vrontou E, Sjulson L, Li H, Hirsh J, Miesenbock G. Writing memories with light-addressable reinforcement circuitry. Cell. 2009; 139:405-415. [PubMed: 19837039]

9. Clyne PJ, Warr CG, Freeman MR, Lessing D, Kim J, Carlson JR. A novel family of divergent seven-transmembrane proteins: candidate odorant receptors in Drosophila. Neuron. 1999; 22:327338. [PubMed: 10069338]

10. Couto A, Alenius M, Dickson BJ. Molecular, anatomical, and functional organization of the Drosophila olfactory system. Curr Biol. 2005; 15:1535-1547. [PubMed: 16139208]

11. Crittenden JR, Skoulakis EM, Han KA, Kalderon D, Davis RL. Tripartite mushroom body architecture revealed by antigenic markers. Learn Mem. 1998; 5:38-51. [PubMed: 10454371]

12. Davis RL. Mushroom bodies and Drosophila learning. Neuron. 1993; 11:1-14. [PubMed: 8338661]

13. Davis RL. Olfactory learning. Neuron. 2004; 44:31-48. [PubMed: 15450158]

14. Davis RL. Olfactory memory formation in Drosophila: from molecular to systems neuroscience. Annu Rev Neurosci. 2005; 28:275-302. [PubMed: 16022597]

15. Davis RL, Cherry J, Dauwalder B, Han PL, Skoulakis E. The cyclic AMP system and Drosophila learning. Mol Cell Biochem. 1995; 149-150:271-278. 
16. de Belle JS, Heisenberg M. Associative odor learning in Drosophila abolished by chemical ablation of mushroom bodies. Science. 1994; 263:692-695. [PubMed: 8303280]

17. Dubnau J, Grady L, Kitamoto T, Tully T. Disruption of neurotransmission in Drosophila mushroom body blocks retrieval but not acquisition of memory. Nature. 2001; 411:476-480. [PubMed: 11373680]

18. Dudai Y, Corfas G, Hazvi S. What is the possible contribution of $\mathrm{Ca}^{2+}$-stimulated adenylate cyclase to acquisition, consolidation and retention of an associative olfactory memory in Drosophila. J Comp Physiol [A]. 1988; 162:101-109.

19. Fishilevich E, Vosshall LB. Genetic and functional subdivision of the Drosophila antennal lobe. Curr Biol. 2005; 15:1548-1553. [PubMed: 16139209]

20. Freund TF, Buzsaki G. Interneurons of the hippocampus. Hippocampus. 1996; 6:347-470. [PubMed: 8915675]

21. Gervasi N, Tchenio P, Preat T. PKA dynamics in a Drosophila learning center: coincidence detection by rutabaga adenylyl cyclase and spatial regulation by dunce phosphodiesterase. Neuron. 2010; 65:516-529. [PubMed: 20188656]

22. Hallem EA, Carlson JR. Coding of odors by a receptor repertoire. Cell. 2006; 125:143-160. [PubMed: 16615896]

23. Han KA, Millar NS, Davis RL. A novel octopamine receptor with preferential expression in Drosophila mushroom bodies. J Neurosci. 1998; 18:3650-3658. [PubMed: 9570796]

24. Han KA, Millar NS, Grotewiel MS, Davis RL. DAMB, a novel dopamine receptor expressed specifically in Drosophila mushroom bodies. Neuron. 1996; 16:1127-1135. [PubMed: 8663989]

25. Honjo K, Furukubo-Tokunaga K. Distinctive neuronal networks and biochemical pathways for appetitive and aversive memory in Drosophila larvae. J Neurosci. 2009; 29:852-862. [PubMed: 19158309]

26. Kaupp UB. Olfactory signalling in vertebrates and insects: differences and commonalities. Nat Rev Neurosci. 2010; 11:188-200. [PubMed: 20145624]

27. Keene AC, Waddell S. Drosophila olfactory memory: single genes to complex neural circuits. Nat Rev Neurosci. 2007; 8:341-354. [PubMed: 17453015]

28. Kim YC, Lee HG, Han KA. D1 dopamine receptor dDA1 is required in the mushroom body neurons for aversive and appetitive learning in Drosophila. J Neurosci. 2007; 27:7640-7647. [PubMed: 17634358]

29. Kim YC, Lee HG, Seong CS, Han KA. Expression of a D1 dopamine receptor dDA1/DmDOP1 in the central nervous system of Drosophila melanogaster. Gene Expr Patterns. 2003; 3:237-245. [PubMed: 12711555]

30. Krashes MJ, DasGupta S, Vreede A, White B, Armstrong JD, Waddell S. A neural circuit mechanism integrating motivational state with memory expression in Drosophila. Cell. 2009; 139:416-427. [PubMed: 19837040]

31. Krashes MJ, Keene AC, Leung B, Armstrong JD, Waddell S. Sequential use of mushroom body neuron subsets during drosophila odor memory processing. Neuron. 2007; 53:103-115. [PubMed: 17196534]

32. Lee T, Lee A, Luo L. Development of the Drosophila mushroom bodies: sequential generation of three distinct types of neurons from a neuroblast. Development. 1999; 126:4065-4076. [PubMed: 10457015]

33. Leiss F, Groh C, Butcher NJ, Meinertzhagen IA, Tavosanis G. Synaptic organization in the adult Drosophila mushroom body calyx. J Comp Neurol. 2009; 517:808-824. [PubMed: 19844895]

34. Levin LR, Han PL, Hwang PM, Feinstein PG, Davis RL, Reed RR. The Drosophila learning and memory gene rutabaga encodes a $\mathrm{Ca}^{2+} /$ calmodulin-responsive adenylyl cyclase. Cell. 1992; 68:479-489. [PubMed: 1739965]

35. Liu X, Davis RL. The GABAergic anterior paired lateral neuron suppresses and is suppressed by olfactory learning. Nat Neurosci. 2009; 12:53-59. [PubMed: 19043409]

36. Liu X, Krause WC, Davis RL. GABAA receptor RDL inhibits Drosophila olfactory associative learning. Neuron. 2007; 56:1090-1102. [PubMed: 18093529]

37. Liu X, Tonegawa S. Optogenetics 3.0. Cell. 2010; 141:22-24. [PubMed: 20371341] 
38. Livingstone MS, Sziber PP, Quinn WG. Loss of calcium/calmodulin responsiveness in adenylate cyclase of rutabaga, a Drosophila learning mutant. Cell. 1984; 37:205-215. [PubMed: 6327051]

39. Mao Z, Davis RL. Eight different types of dopaminergic neurons innervate the Drosophila mushroom body neuropil: anatomical and physiological heterogeneity. Front Neural Circuits. 2009; 3:5. [PubMed: 19597562]

40. Mao Z, Roman G, Zong L, Davis RL. Pharmacogenetic rescue in time and space of the rutabaga memory impairment by using gene-switch. Proc Natl Acad Sci USA. 2004; 101:198-203. [PubMed: 14684832]

41. Masse NY, Turner GC, Jefferis GS. Olfactory information processing in Drosophila. Curr Biol. 2009; 19:R700-R713. [PubMed: 19706282]

42. McGuire SE, Le PT, Davis RL. The role of Drosophila mushroom body signaling in olfactory memory. Science. 2001; 293:1330-1333. [PubMed: 11397912]

43. McGuire SE, Le PT, Osborn AJ, Matsumoto K, Davis RL. Spatiotemporal rescue of memory dysfunction in Drosophila. Science. 2003; 302:1765-1768. [PubMed: 14657498]

44. McGuire SE, Mao Z, Davis RL. Spatiotemporal gene expression targeting with the TARGET and gene-switch systems in Drosophila. Sci STKE. 2004; 2004:pl6. [PubMed: 14970377]

45. Miesenbock G. The optogenetic catechism. Science. 2009; 326:395-399. [PubMed: 19833960]

46. Moult PR. Neuronal glutamate and GABAA receptor function in health and disease. Biochem Soc Trans. 2009; 37:1317-1322. [PubMed: 19909268]

47. Nassel DR, Elekes K. Aminergic neurons in the brain of blowflies and Drosophila: dopamine- and tyrosine hydroxylase-immunoreactive neurons and their relationship with putative histaminergic neurons. Cell Tissue Res. 1992; 267:147-167. [PubMed: 1346506]

48. Ng M, Roorda RD, Lima SQ, Zemelman BV, Morcillo P, Miesenbock G. Transmission of olfactory information between three populations of neurons in the antennal lobe of the fly. Neuron. 2002; 36:463-474. [PubMed: 12408848]

49. Pagani MR, Oishi K, Gelb BD, Zhong Y. The phosphatase SHP2 regulates the spacing effect for long-term memory induction. Cell. 2009; 139:186-198. [PubMed: 19804763]

50. Pascual A, Preat T. Localization of long-term memory within the Drosophila mushroom body. Science. 2001; 294:1115-1117. [PubMed: 11691997]

51. Perez-Orive J, Mazor O, Turner GC, Cassenaer S, Wilson RI, Laurent G. Oscillations and sparsening of odor representations in the mushroom body. Science. 2002; 297:359-365. [PubMed: 12130775]

52. Quinn WG, Harris WA, Benzer S. Conditioned behavior in Drosophila melanogaster. Proc Natl Acad Sci USA. 1974; 71:708-712. [PubMed: 4207071]

53. Riemensperger T, Voller T, Stock P, Buchner E, Fiala A. Punishment prediction by dopaminergic neurons in Drosophila. Curr Biol. 2005; 15:1953-1960. [PubMed: 16271874]

54. Roman G, Endo K, Zong L, Davis RL. P[Switch], a system for spatial and temporal control of gene expression in Drosophila melanogaster. Proc Natl Acad Sci USA. 2001; 98:12602-12607. [PubMed: 11675496]

55. Schroll C, Riemensperger T, Bucher D, Ehmer J, Voller T, Erbguth K, Gerber B, Hendel T, Nagel G, Buchner E, Fiala A. Light-induced activation of distinct modulatory neurons triggers appetitive or aversive learning in Drosophila larvae. Curr Biol. 2006; 16:1741-1747. [PubMed: 16950113]

56. Schwaerzel M, Monastirioti M, Scholz H, Friggi-Grelin F, Birman S, Heisenberg M. Dopamine and octopamine differentiate between aversive and appetitive olfactory memories in Drosophila. J Neurosci. 2003; 23:10495-10502. [PubMed: 14627633]

57. Sinakevitch I, Strausfeld NJ. Comparison of octopamine-like immunoreactivity in the brains of the fruit fly and blow fly. J Comp Neurol. 2006; 494:460-475. [PubMed: 16320256]

58. Thum AS, Jenett A, Ito K, Heisenberg M, Tanimoto H. Multiple memory traces for olfactory reward learning in Drosophila. J Neurosci. 2007; 27:11132-11138. [PubMed: 17928455]

59. Tomchik SM, Davis RL. Dynamics of learning-related cAMP signaling and stimulus integration in the Drosophila olfactory pathway. Neuron. 2009; 64:510-521. [PubMed: 19945393]

60. Tully T, Quinn WG. Classical conditioning and retention in normal and mutant Drosophila melanogaster. J Comp Physiol [A]. 1985; 157:263-277. 
61. Turner GC, Bazhenov M, Laurent G. Olfactory representations by Drosophila mushroom body neurons. J Neurophysiol. 2008; 99:734-746. [PubMed: 18094099]

62. Wang JW, Wong AM, Flores J, Vosshall LB, Axel R. Two-photon calcium imaging reveals an odorevoked map of activity in the fly brain. Cell. 2003; 112:271-282. [PubMed: 12553914]

63. Wang Y, Guo HF, Pologruto TA, Hannan F, Hakker I, Svoboda K, Zhong Y. Stereotyped odorevoked activity in the mushroom body of Drosophila revealed by green fluorescent proteinbased $\mathrm{Ca}^{2+}$ imaging. J Neurosci. 2004; 24:6507-6514. [PubMed: 15269261]

64. Wang Y, Mamiya A, Chiang AS, Zhong Y. Imaging of an early memory trace in the Drosophila mushroom body. J Neurosci. 2008; 28:4368-4376. [PubMed: 18434515]

65. Yasuyama K, Meinertzhagen IA, Schurmann FW. Synaptic organization of the mushroom body calyx in Drosophila melanogaster. J Comp Neurol. 2002; 445:211-226. [PubMed: 11920702]

66. Yu D, Akalal DB, Davis RL. Drosophila alpha/beta mushroom body neurons form a branchspecific, long-term cellular memory trace after spaced olfactory conditioning. Neuron. 2006; 52:845-855. [PubMed: 17145505]

67. Yu D, Keene AC, Srivatsan A, Waddell S, Davis RL. Drosophila DPM neurons form a delayed and branch-specific memory trace after olfactory classical conditioning. Cell. 2005; 123:945-957. [PubMed: 16325586]

68. Yu D, Ponomarev A, Davis RL. Altered representation of the spatial code for odors after olfactory classical conditioning; memory trace formation by synaptic recruitment. Neuron. 2004; 42:437449. [PubMed: 15134640]

69. Zars T, Fischer M, Schulz R, Heisenberg M. Localization of a short-term memory in Drosophila. Science. 2000; 288:672-675. [PubMed: 10784450] 


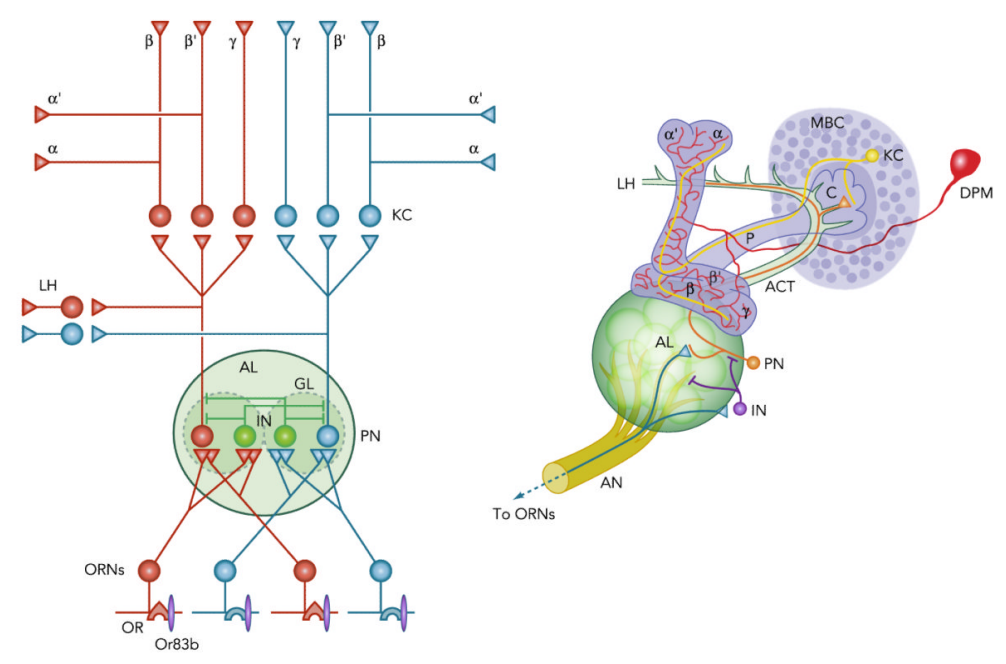

FIGURE 1.

Cellular and anatomical organization of the Drosophila olfactory nervous system $A$ : schematic representation of the neuronal circuitry. Each olfactory receptor neuron (ORN) expresses only one type of odorant receptor (OR) in its apical dendrites together with Or83b. Two types of ORNs are schematized here, red and blue. All ORN expressing the same OR project to only one glomerulus $(\mathrm{Gl})$ of the antennal lobe $(\mathrm{AL})$. In this brain region, ORNs synapse onto projection neurons (PN) and local excitatory or inhibitory interneurons (IN). PNs send their axons to the MB neurons [also known as Kenyon cells (KC)] and to the lateral horn (LH). Three classes of MB neurons have been described according to their axonal collaterals $\left(\alpha / \beta, \alpha^{\prime} / \beta^{\prime}\right.$, and $\left.\gamma\right)$. $B$ : anatomical organization of the olfactory system. For simplicity, only one ORN axon (blue), one PN (orange), one IN (purple), and one MB neuron (yellow) have been superimposed onto a schematic diagram of one hemisphere of the fly brain. The ORNs extend their axons to the AL through the antennal nerve (AN). ORNs synapse with PNs and INs whose cell bodies reside at the periphery of AL. The PNs send axo-dendritic processes into the AL glomeruli and extend axons to the calyx (C) by way of the antenno-cerebral tract (ACT) to synapse on the dendritic processes of MB cells. The axons extended by MB cells follow the pedunculus (P) to reach the MB lobes. In this figure, only one $\alpha / \beta$ neuron is shown with its projections into one collateral of the $a$ lobe and another into the $\beta$ lobe. 

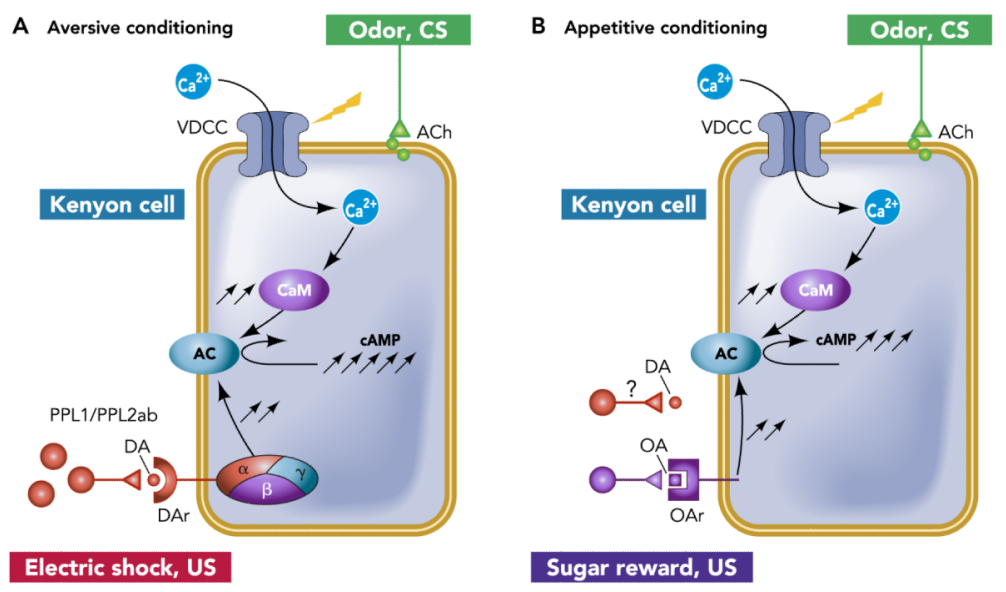

FIGURE 2.

Schematic representation of some of the molecular mechanisms involved in aversive and appetitive olfactory conditioning $A$ : aversive conditioning. CS information is presented to the MB neurons by the PNs. PNs release acetylcholine (ACh) at synapses with MB cells causing voltage-gated calcium channels to open. The increase in intracellular $\mathrm{Ca}^{2+}$ concentration produces more calmodulin $(\mathrm{CaM})$ bound with $\mathrm{Ca}^{2+}$. Calcium-bound calmodulin then activates adenylyl cyclase (AC), producing an elevation in cAMP (represented by 2 black arrows). The US information is presented to the MB neurons by PPL1/PPL2ab neurons, which release DA onto MB neurons. Activation of DA receptors also increases cAMP levels ( 2 black arrows) through the activation of a heterotrimeric $\mathrm{G}$ protein coupled to AC. With the coincident activation of the CS and the US pathways during conditioning, a synergistic increase in cAMP occurs (5 black arrows), providing the necessary information in the MB neurons for encoding the CS/US temporal coincidence. $B$ : appetitive conditioning. For appetitive conditioning, the same CS pathway is induced in the MB neurons. The US information may be represented by OA release onto the MB neurons that also stimulates AC. DA neurons appear also to have a role in appetitive conditioning, but further research is required to make this clear. For appetitive conditioning, the coincident application of CS and US (OA) produces a subadditive increase in postsynaptic cAMP (3 black arrows). 


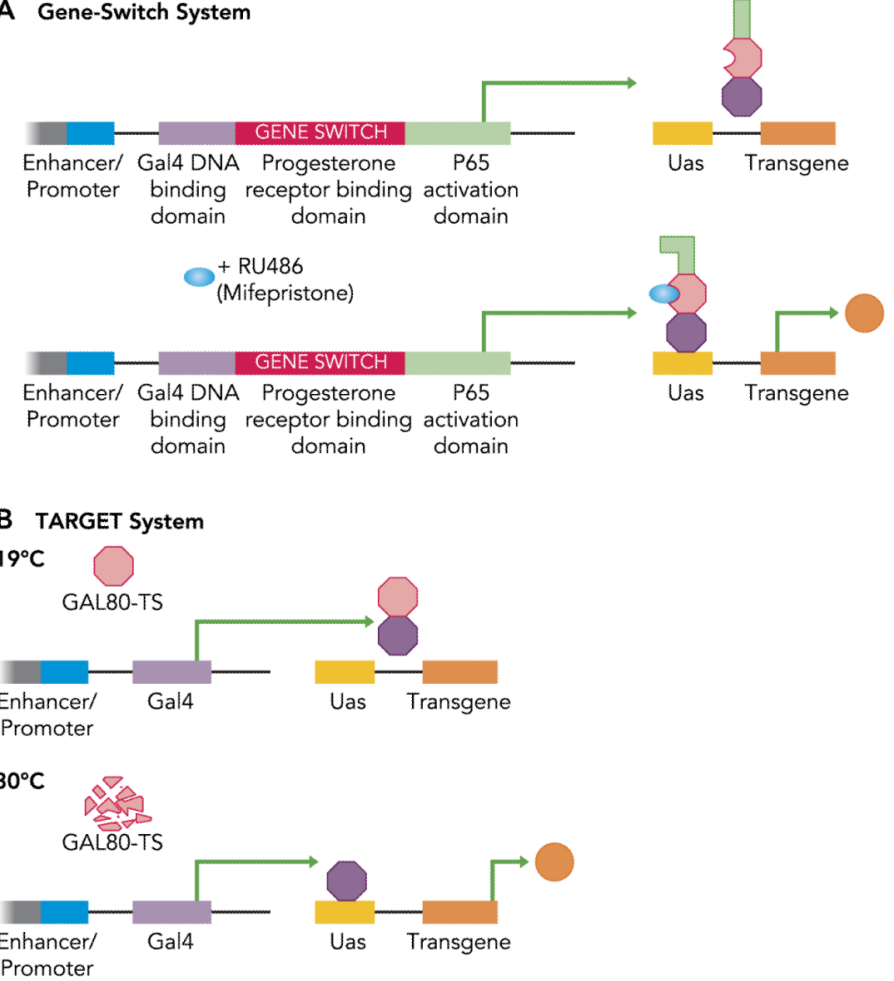

FIGURE 3.

The Gal4 system, enhancer trapping, TARGET, and gene switch Many different experimental methods have been developed using Drosophila to "bump" the system to understand the underlying biology. Some related methods include the Gal4/Uas system, enhancer trapping, TARGET, and gene switch $(5,40,43,44,54)$. The yeast transcription factor, GAL4, when expressed in Drosophila will bind to the sequences it recognizes [upstream activating sequences (Uas)] and promote the transcription of adjacent DNA sequences (5). By screening randomly inserted transposons carrying Gal4 downstream of a minimal promoter it is possible to capture the activity of genomic enhancers that will then drive the expression of GAL4 exclusively within identifiable subsets of neurons. By crossing Gal4 driver lines with strains expressing a gene of interest downstream of a UAS cassette, it is possible to restrict the expression of this gene in a selected population of neurons. This is the essence of enhancer trapping utilizing the binary Gal4/Uas system. One of the more useful refinements has been the development of methods to control the expression of transgenes in both time and space. We developed two different techniques for this. $A$ : the first system is based on a GAL4-progesterone receptor chimera, known as gene switch $(40,54)$. This chimeric protein contains a fusion of the GAL4 DNA binding domain with the p65 activation domain and the ligand-binding domain of the progesterone receptor. This fusion protein functions as a ligand-stimulated transcription factor. In the presence of ligand, the gene-switch molecule adopts an active state and binds to Uas sequences to transcribe the flanking gene. This system provides temporal control over transgene expression by supplying the ligand mifepristone (RU486). It provides spatial control over transgene expression by using a cloned promoter with its own enhancers or enhancer activity usurped by enhancer trapping. $B$ : the TARGET system employs the ubiquitous expression of a temperature-sensitive version of GAL80 $\left(\mathrm{GAL}^{\mathrm{ts}}\right)$, an effective inhibitor of GAL4 at permissive temperatures. Introducing a GAL80 ${ }^{\text {ts }}$ transgene into Drosophila allows the experimenter to regulate GAL4 activity in a temperature-dependent manner. This provides a 
general method for achieving temporal gene expression with temperature and spatial control by using a cloned promoter with its own enhancers or enhancer activity usurped by enhancer trapping. 